\title{
On the Structure of the Reversibly Oxidized and Reduced Group of Sperm Antagglutins
}

\author{
P. E. LINDAHL and S. ROSS
}

Institute of Zoophysiology, University of Uppsala, Sweden

\begin{abstract}
When sperm antagglutins are inactivated by oxidation a carbonyl group is formed. This has been detected by blocking with sodium bisulphite of the reactivation of the antagglutin by reducing agents. The oxidized biologically inactive sperm antagglutins are reduced by DPNH. This reaction seems to be non-enzymatic, and to be blocked by diacetyl and lactate. The location of the easily reducible carbonyl group in the oxidized antagglutin molecule is discussed.
\end{abstract}

Tn semen from most mammals a factor occurs which prevents head-to-head agglutination of the spermatozoa. This anti-agglutinating factor, named male sperm antagglutin, is formed in the prostatic gland in cattle ${ }^{1}$ and man ${ }^{2}$. Male sperm antagglutin has been isolated and purified by precipitation with ammonium sulphate and chromatography on calcium carbonate ${ }^{3}$. It is a proteid with an active group containing carbohydrate ${ }^{1,3}$, sulphuric acid residues 4,5 , and a probably carbocyclic compound ${ }^{5,6,7}$.

Also in the female genital tract of several mammals a sperm anti-agglutinating factor, named female sperm antagglutin, has been detected and isolated by chromatography on silica ${ }^{8}$. It contains no protein, but seems to be very similar to the active group of the male sperm antagglutin. However, no sulphuric acid residues could be detected ${ }^{8}$.

Both these sperm antagglutins are inactivated by being kept in aqueous solution at room temperature in contact with air. However, this process is very much accelerated by bubbling oxygen through the solution after addition of a minute amount of platinum black. When a reducing agent as sodium thioglycolate, sodium ascorbate, or hydrogen and platinum black is added to these biological inactive solutions the activity is recovered ${ }^{1,3}$. The inactivation of sperm antagglutins is thus brought about by oxidation of some group in the antagglutin molecules.

As the oxidation and the inactivation of the sperm antagglutins occur simultaneously, it was of interest to try to acquire some knowledge about the chemical structure of the group of the antagglutin molecule which is so 
easily reversibly oxidized and reduced. To obtain such information we have to study the biological activity of pretreated samples of sperm antagglutin. By adding different reagents with known qualities to oxidized, biologically inactive sperm antagglutin some substances with the power of inhibiting the reactivation of the oxidized antagglutin might possibly be found. In case the same reagent, added to reduced antagglutin, should not influence the biological activity of the antagglutin, it could be concluded that the reagent reacts in some way with the oxidized form of the group of the antagglutin molecule which is reversibly oxidized and reduced, by preventing its reduction. In its oxidized form this group might be quinonelike or it might be a disulphide, carbonylic, carboxylic, epoxy, or ethylenic group. Since female sperm antagglutin has been shown to contain no sulphur ${ }^{8}$, disulphide groups can be excluded from discussion. Quinones as well as carbonyls should react with carbonylic reagents, although in somewhat different ways. We have therefore used for this purpose sodium bisulphite, and also tried some other carbonyl reagents.

All substances so far studied with the ability of reducing the oxidized sperm antagglutins have an oxidation-reduction potential $\left(E_{\mathrm{o}}^{\prime}\right)$ equal to 0.06 or lower ${ }^{9}$. Among these sodium thioglycolate as well as reduced diphosphopyridine nucleotide (DPNH) were found to induce very high biological activity. Combined with one of several dehydrogenases DPNH has the ability of reducing different carbonyl compounds. On the other hand the possibility is not excluded that DPNH might by itself reduce oxidized antagglutin, although it is known to be rather inert. We have therefore tried to decide whether DPNH, when reducing oxidized sperm antagglutin is acting by itself or combined with an enzyme.

\section{MATERIALS}

The male sperm antagglutin was prepared according to Lindahl and Kihlström ${ }^{3}$. The relatively pure preparations were used in aqueous solution of about $50 \mu \mathrm{g}$ antagglutin per ml, estimated according to Lindahl and Kihlström ${ }^{3}$. The female sperm antagglutin which was prepared according to Lindahl and Nilsson ${ }^{8}$ has been used in an aqueous solution equivalent in its biological activity to the above mentioned male sperm antagglutin solution. The sperm antagglutin solutions were oxidized by aeration during one hour in presence of platinum black. Sodium thioglycolate $\left(4.4-5.7 \times 10^{-4} \mathrm{M}\right)$ was regularly used as reducing agent in experiments in which reactions with reduced antagglutins were studied. When investigating the reduction of oxidized antagglutin by DPNH we used this compound, enzymatically reduced (Sigma), in a concentration of $5.7 \times 10^{-4} \mathrm{M}$.

Bull spermatozoa were used for tests on biological activity. The spermatozoa in 0.5 $\mathrm{ml}$ semen were washed three times by suspending them in $8 \mathrm{ml}$ of the diluter of Phillips and Spitzer ${ }^{10}$, slightly modified, and by centrifugation. This diluter was prepared by mixing equal amounts of two solutions, one containing $0.6 \%$ glucose, and $0.8 \%$ galactose, and the other $0.2 \% \mathrm{KH}_{2} \mathrm{PO}_{4}$ and $0.2 \% \mathrm{Na}_{2} \mathrm{HPO}_{1} 12 \mathrm{H}_{2} \mathrm{O}$, both made up with water twice distilled in glass, and autoclaved. This is here named diluter I. Another diluter with the double osmotic pressure must also be used to compensate for the very low osmotic pressure of the dilute antagglutin solutions and of the reagent solutions used. This diluter here named diluter II, contains twice as much solids as diluter I. - All reagents with exception of diacetyl were of pro analysi quality. All solutions have been freshly prepared every day. 


\section{EXPERIMENTS AND RESULTS}

The experiments are arranged in such a way that conclusions may be drawn from comparisons between values of anti-agglutination index, AAI, found. Thus the AAI of any sample of antagglutin is determined with a control containing all the reagents with the exception of the antagglutin, and in the same final concentrations as in the relevant sample. In cases in which one or more reagents are brought to react with the sperm antagglutin the sample is prepared in the following way: To $0.03 \mathrm{ml}$ of a solution of sperm antagglutin in a test tube an equal volume of solution of the reagent to be studied is added, the tube shaken, and left for $10 \mathrm{~min}$ at room temperature (time of reaction, cf. tables). The same volume of a second reagent solution may be added, the mixture shaken, and left for another $10 \mathrm{~min}$, and in a few cases a third reagent may be added in the same way. A volume of diluter II equal to that of the mixture already in the tube is added, and the final volume (cf. tables) minus $0.03 \mathrm{ml}$ made up with diluter I. Then $0.03 \mathrm{ml}$ of the sperm suspension is added. Each addition is followed by thorough mixing. As the reduction of oxidized sperm antagglutin is a comparatively fast process a "reaction time" of less than $10 \mathrm{~min}$ is generally allowed to pass after the addition of his reagent, in case it being the last one, the time elapsing until the beginning of the counting being long enough.

The percentage of spermatozoa agglutinated head-to-head $\left(\mathrm{P}_{2}\right)$ in the experimental sample and the corresponding percentage $\left(\mathrm{P}_{1}\right)$ in the control are determined in a haemocytometer as described by Lindahl and Nilsson ${ }^{8}$. The anti-agglutination index (AAI) is expressed according to the formula:

$$
\mathrm{AAI}=\frac{\mathrm{P}_{2}-\mathrm{P}_{1}}{\mathrm{P}_{1}}
$$

Differences in AAI determined with this method, when greater than 0.1 are generally significant. Negative values of AAI of oxidized antagglutin preparations are the result of agglutinating impurities, whereas positive values depend upon incomplete oxidation. Real quantitative comparisons of values of AAI's are possible only, when the same antagglutin preparation and the same spermatozoa have been used. However, considering that the errors in the many measurings of small amounts of liquids in some samples may accumulate, still greater differences may appear between samples which might be expected to give identical AAI values.

Reaction between oxidized sperm antagglutin and sodium bisulphite. When a dilute aqueous solution of sodium bisulphite is added to oxidized male or female sperm antagglutin, the biological activity remains zero also after addition of sodium thioglycolate (Table 1:III). Reduced sperm antagglutins on the other hand maintain their biological activity after addition of the sodium bisulphite solution (Table $1: \mathrm{V}$ ). The oxidized, but not the reduced form of the sperm antagglutins obviously reacts with sodium bisulphite, the complex formed preventing reduction of the antagglutins. The reaction between oxidized sperm antagglutins and sodium bisulphite is, however, reversible as is shown by the following: Addition only of sodium pyruvate which has a large affinity to bisulphite, and thus also to that in the complex formed by the 
Table 1. Blocking of male $(a-b)$ and female (c) sperm antagglutin with sodium bisulphite. I-VII.

A. Composition of test samples $(1$ volume $=0.03 \mathrm{ml}$ ). Total volume $0.27 \mathrm{ml}$.

\begin{tabular}{|c|c|c|c|c|c|c|c|}
\hline $\begin{array}{c}\text { Test } \\
\text { samples }\end{array}$ & $\begin{array}{c}\text { Ox. } \\
\text { antagglutin } \\
\sim 1 \mu \mathrm{g} / \mathrm{vol} .\end{array}$ & $\begin{array}{c}\mathrm{NaHSO}_{3} \\
1.6 \times 10^{-2} \mathrm{M}\end{array}$ & $\begin{array}{l}\text { Na thio- } \\
\text { glycolate } \\
4 \times 10^{-3} \mathrm{M}\end{array}$ & $\begin{array}{l}\text { Na pyru- } \\
\text { vate } \\
3 \times 10^{-2} \mathrm{M}\end{array}$ & $\underset{I}{\text { Diluter }}$ & $\underset{\text { II }}{\text { Diluter }}$ & $\begin{array}{l}\text { Sperm } \\
\text { susp. }\end{array}$ \\
\hline I & 1 & & & & 6 & 1 & 1 \\
\hline II & 1 & 1 & & & 4 & 2 & 1 \\
\hline III & 1 & 1 & 1 & & 2 & 3 & 1 \\
\hline IV & 1 & & 1 & & 4 & 2 & 1 \\
\hline $\mathrm{V}$ & 1 & 1 & 1 & & 2 & 3 & 1 \\
\hline VI & 1 & 1 & & 1 & 2 & 3 & 1 \\
\hline VII & 1 & 1 & 1 & 1 & & 4 & 1 \\
\hline
\end{tabular}

B. Order of adding reagents, and AAI:s found.

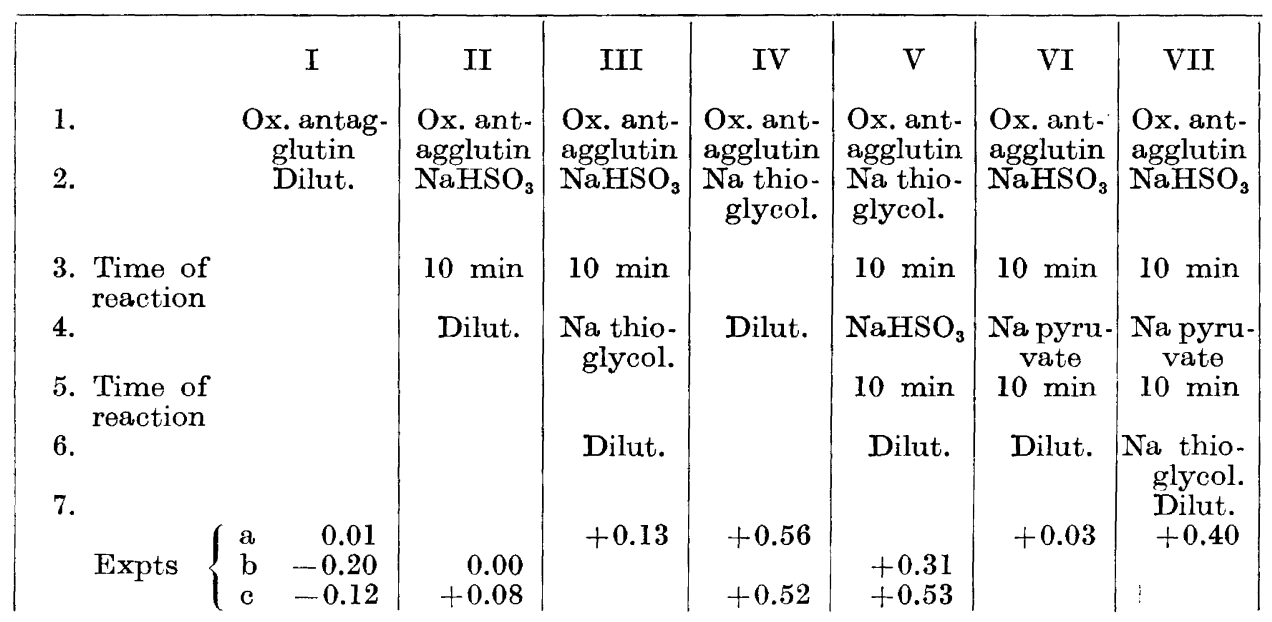

oxidized antagglutin and sodium bisulphite, does not change the biological activity from zero (Table 1:VI). When, however, the reducing agent sodium thioglycolate is then added, the activity is immediately recovered (Table 1:VII). The reaction studied may thus be written:

oxidized antagglutin $+\mathrm{NaHSO}_{3} \rightleftharpoons$ oxidized antagglutin $\mathrm{H} \cdot \mathrm{SO}_{3} \mathrm{Na}$

Sodium bisulphite is a wellknown carbonyl reagent which reacts reversibly. It is thus probable that the oxidized sperm antagglutins contain at least one carbonyl group which is reduced to a hydroxygroup by the reducing agent when the antagglutins are reactivated. It is further obvious that the velocity with which bisulphite combines with the carbonyl must be much higher than that of the reduction effected on the same group. The latter is readily reduced by sulphite ${ }^{9}$.

Sperm antagglutins reacting with phenylhydrazine hydrochloride and hydroxylamine hydrochloride, respectively. Both oxidized (Table 2:II) and reduced 
Table 2. Blocking of oxidized (II) and reduced (IV) sperm antagglutin with phenylhydrazine hydrochloride and hydroxylamine hydrochloride $\left(2.3 \times 10^{-3} \mathrm{M}\right)$.

A. Composition of test samples $(1$ vol. $=0.03 \mathrm{ml}$ ). Total volume $0.21 \mathrm{ml}$.

\begin{tabular}{|c|c|c|c|c|c|}
\hline $\begin{array}{c}\text { Test } \\
\text { samples }\end{array}$ & $\begin{array}{c}\text { Ox. antag- } \\
\text { glutin } \\
\sim \mu \mathrm{g} / \mathrm{ml} l\end{array}$ & $\begin{array}{c}\text { Studied } \\
\text { compound } \\
1.6 \times 10^{-2} \mathrm{M}\end{array}$ & $\begin{array}{c}\text { Diluter } \\
\text { I }\end{array}$ & $\begin{array}{c}\text { Diluter } \\
\text { II }\end{array}$ & $\begin{array}{c}\text { Sperm } \\
\text { susp. }\end{array}$ \\
II & 1 & 1 & 4 & 1 & 1 \\
III & 1 & 1 & 2 & 2 & 1 \\
IV & 1 & 1 & 2 & 2 & 1
\end{tabular}

B. Order of adding reagents, and AAI:s found.

\begin{tabular}{|c|c|c|c|c|}
\hline $\begin{array}{l}\text { 1. } \\
\text { 2. } \\
\text { 3. Time of reaction } \\
\text { 4. } \\
\text { 5. Dialysis }\left(4 \times 10^{-3} \mathrm{M}\right. \\
\text { Nathioglycolate solution) } \\
\text { 6. } \\
\text { Phenylhydrazin } \cdot \mathrm{HCl} \\
\text { Hydroxylamin } \cdot \mathrm{HCl}\end{array}$ & $\begin{array}{c}\text { I } \\
\text { Ox. antag- } \\
\text { glutin } \\
\text { Diluters }\end{array}$ & $\begin{array}{l}12 \mathrm{~h} \\
\text { Diluters } \\
+0.01 \\
+0.05\end{array}$ & $\begin{array}{c}12 \mathrm{~h} \\
\text { Diluters } \\
+0.37\end{array}$ & $\begin{array}{c}\text { IV } \\
\text { Ox. antag- } \\
\text { glutin } \\
\text { Na thio- } \\
\text { glycolate } \\
10 \text { min } \\
\text { Studied } \\
\text { compound } \\
12 \mathrm{~h}\end{array}$ \\
\hline
\end{tabular}

* Tested against other spermatozoa than samples II-IV.

(Table 2:IV) male sperm antagglutin are inactivated by these two carbonyl reagents. Since these reagents react with sugars, we had to replace the sugars of the diluters by sodium chloride when determining biological activities. In order to prevent that the effects observed are due to influences of the reagents on the spermatozoa the experiments were performed with male sperm antagglutin, and the reaction mixtures II and IV of Table 2 dialyzed against $4 \times 10^{-3} \mathrm{M}$ sodium thioglycolate solution over night. Thus the surplus of the reagents was removed before the addition of the diluters and the spermatozoa, no thioglycolate solution being added. The activity of the oxidized antagglutin was estimated immediately (Table 2:I), and another volume of this solution, diluted with 2 volumes of distilled water, was dialyzed together with samples II and IV to give the AAI of untreated reduced antagglutin. The inactivation even of the reduced male sperm antagglutin by these compounds probably depends on a reaction with the sugar residues in the antagglutin molecule. Male sperm antagglutin is known to give a positive reaction with benzidine ${ }^{3}$ which indicates the presence of reducing sugar. Experiments with these two carbonyl reagents therefore do not give any information as to the nature of the reversibly oxidized and reduced group. - In special control experiments the treatment of spermatozoa with the two relevant 
reagents was found to be without any effect upon the estimations of the biological activity of female antagglutin. An experiment with phenylhydrazine on the same lines, however, with exclusion of the dialysis was performed with reduced female antagglutin with the same result. Here a reaction with sugar residues is less probable, as no positive reaction on reducing sugars with benzidine has been obtained ${ }^{8}$. The inactivation of reduced female sperm antagglutin by phenylhydrazine may possibly indicate the existence of a second carbonyl, much more resistant against reducing agents and not localized in the saccharide constituent. However, a possible coupling of this carbonyl with bisulphite should not result in inactivation.

The non-enzymatic reduction of oxidized sperm antagglutins with $D P N H$. In order to be able to decide, whether or not an enzyme is involved in the oxidation of DPNH by oxidized antagglutin, experiments were performed with female sperm antagglutin as this does not contain any protein, and thus is free from contaminating enzymes. The spermatozoa used in the tests for biological activity represent another possible source of enzymes. In order to exclude the participation of enzymes of the test spermatozoa in the studied reaction the experiments were arranged in such a way that the reaction between DPNH and the oxidized antagglutin takes place before the addition of the sperm suspension. This was secured by adding bisulphite to the mixture of the two compounds, blocking in this way any oxidized antagglutin before the addition of the spermatozoa. Thus a sample (Table 3:II) was prepared in the following way: Sodium bisulphite was added to female sperm antagglutin. Ten minutes later DPNH, and after another $10 \mathrm{~min}$ the diluters and the sperm suspension were introduced into the mixture. In another sample (Table 3:III) DPNH

Table 3. Inhibition of the power of DPNH $\left(\sim 6 \times 10^{-4} \mathrm{M}\right)$ to reduce oxidized female sperm antagglutin in presence of sodium bisulphite $\left(2.3 \times 10^{-8} \mathrm{M}\right)$.

A. Composition of test samples (1 vol. $0.03 \mathrm{ml}$ ). Total volume $0.21 \mathrm{ml}$.

\begin{tabular}{|c|c|c|c|c|c|c|}
\hline $\begin{array}{c}\text { Test } \\
\text { samples }\end{array}$ & $\begin{array}{c}\text { Ox. antag- } \\
\text { glutin } \\
\sim 1 \mu \mathrm{g} / \mathrm{vol} .\end{array}$ & $\begin{array}{c}\mathrm{NaHSO}_{3} \\
1.6 \times 10^{-2} \mathrm{M}\end{array}$ & $\begin{array}{c}\text { DPNH } \\
4 \times 10^{-3} \mathrm{M}\end{array}$ & $\underset{\text { I }}{\text { Diluter }}$ & $\begin{array}{c}\text { Diluter } \\
\text { II }\end{array}$ & $\begin{array}{l}\text { Sperm } \\
\text { susp. }\end{array}$ \\
\hline$\underset{\text { III }}{\text { II }}$ & $\begin{array}{l}1 \\
1 \\
1 \\
1\end{array}$ & $\begin{array}{l}1 \\
1\end{array}$ & $\begin{array}{l}1 \\
1 \\
1\end{array}$ & 4 & $\begin{array}{l}1 \\
3 \\
3 \\
2\end{array}$ & $\begin{array}{l}1 \\
1 \\
\text { I } \\
1\end{array}$ \\
\hline
\end{tabular}

B. Order of adding reagents, and AAI:s found.

\begin{tabular}{|c|c|c|c|c|}
\hline $\begin{array}{l}\text { 1. } \\
\text { 2. Time of reaction } \\
\text { 3. Tim } \\
\text { 5. Time of reaction } \\
\text { 6. }\end{array}$ & $\begin{array}{c}\mathrm{I} \\
\text { Ox. } \\
\text { antagglutin } \\
\text { Diluters }\end{array}$ & $\begin{array}{c}\text { II } \\
\text { Ox. } \\
\text { antagglutin } \\
\mathrm{NaHSO}_{3} \\
10 \mathrm{~min} \\
\text { DPNH } \\
10 \mathrm{~min} \\
\text { Diluters } \\
-0.12\end{array}$ & $\begin{array}{c}\text { III } \\
\text { Ox. } \\
\text { antagglutin } \\
\text { DPNH } \\
10 \text { min } \\
\text { NaHSO }_{3} \\
10 \text { min } \\
\text { Diluters } \\
+0.33\end{array}$ & $\begin{array}{c}\text { IV } \\
\text { Ox. } \\
\text { antagglutin } \\
\text { DPNH } \\
\text { 10 min } \\
\text { Diluters } \\
+0.45\end{array}$ \\
\hline
\end{tabular}

Acta Chem. Scand. 13 (1959) No. 8 
was mixed with the antagglutin solution, and sodium bisulphite added only 10 min later. From Table 3 it is obvious that in the first case the sodium bisulphite blocks the reduction of the antagglutin, whereas in the second case the antagglutin is reduced by DPNH. The reduction of oxidized female sperm antagglutin by DPNH thus seems to be non-enzymatic, and this probably also applies to the male sperm antagglutin.

Spectrophotometric recording of the oxidation of $D P N H$ by oxidized male sperm antagglutin. A few experiments were performed in order to study the decrease in the absorption maximum of DPNH at $340 \mathrm{~m} \mu$, expected to occur, when oxidized sperm antagglutin is reduced by DPNH. The result of such an experiment is shown in Table 4 . To $0.7 \mathrm{mg}$ of oxidized male sperm antag-

Table 4. Decrease in optical density at $340 \mathrm{~m} \mu$ during incubation of DPNH $(0.3 \mu$ mole $)$ with oxidized male sperm antagglutin $(0.7 \mathrm{mg})$ in bidistilled water $(2.9 \mathrm{ml})$. Temperature $22^{\circ} \mathrm{C}$.

$\begin{array}{lccccc}\text { Time in } \min & 0 & 1 & 2 & 3 & 5 \\ -\Delta D_{340 \mu} & 0.000 & 0.020 & 0.028 & 0.032 & 0.040\end{array}$

glutin in $2.8 \mathrm{ml}$ of distilled water $0.1 \mathrm{ml}$ of $3 \times 10^{-3} \mathrm{M} \mathrm{DPNH}$ was added in a quarz cell. Immediately after mixing the absorption at $340 \mathrm{~m} \mu$ was read on a Beckmann DU spectrophotometer against a blanc containing $0.1 \mathrm{ml}$ of $3 \times 10^{-3} \mathrm{M}$ DPNH and $2.8 \mathrm{ml}$ of distilled water. The absorption of the sample was then read after $1,2,3$, and $5 \mathrm{~min}$, and was found to decrease during this time in relation to that of the blank, DPNH being oxidized to DPN by the sperm antagglutin (Table 4).

Inhibition of the reduction of oxidized sperm antagglutins with DPNH by diacetyl and sodium lactate. Starting from the idea that the reaction between DPNH and oxidized sperm antagglutin could be involved in the regulation of sperm metabolism we investigated the influence of a substance, reacting as metabolite with the diphosphopyridine nucleotide, viz. lactate, and diacetyl.

If diacetyl or sodium lactate in concentrations of $4.5 \times 10^{-3} \mathrm{M}$ are added to a solution of oxidized sperm antagglutin before the addition of DPNH, the biological activity is not restored (Table 5:III, expts b and c). If other reducing agents, like sodium thioglycolate or sodium ascorbate, are used neither diacetyl nor sodium lactate inhibit the reduction (Table 5:IV). Diacetyl obviously is the more potent of the two compounds in this respect. In another experiment (Table 5:III, expt d) increased quantities of diacetyl were mixed with a constant quantity of antagglutin prior to the addition of DPNH. In this case the inhibition of the reduction of the oxidized antagglutin was complete, when the added quantity of diacetyl was about equivalent to the amount of DPNH present (Table 5:III, expt $\Theta$ ). It is probable that the inhibition of the reduction of antagglutin by DPNH is dependent on some interaction between DPNH and diacetyl or sodium lactate, respectively, which brings about a blocking in the reducing power of DPNH. In the oxidized state diphosphopyridine nucleotide forms additive compounds with dihydroxyacetone and similar $\alpha$-hydroxy carbonyl compounds ${ }^{11}$. Additive compounds between DPNH and carbonyl compounds seem not to be known. 
Table 5. Blocking with diacetyl or sodium lactate of the oxidation of DPNH by oxidized male sperm antagglutin.

A. Composition of test samples (1 vol. $0.03 \mathrm{ml}$ ). Total volume $0.21 \mathrm{ml}$.

\begin{tabular}{|c|c|c|c|c|c|c|c|}
\hline $\begin{array}{c}\text { Test } \\
\text { samples }\end{array}$ & $\begin{array}{c}\text { Ox. } \\
\text { antagglutin } \\
\sim 1 \mu \mathrm{g} / \mathrm{vol} .\end{array}$ & $\begin{array}{c}\text { Studied } \\
\text { compound } \\
3 \times 10^{-3}- \\
3 \times 10^{-2} \mathrm{M}\end{array}$ & $\begin{array}{c}\text { DPNH } \\
4 \times 10^{-3} \mathrm{M}\end{array}$ & $\begin{array}{l}\text { Na thio- } \\
\text { glycolate } \\
4 \times 10^{-3} \mathrm{M}\end{array}$ & $\underset{I}{\text { Diluter }}$ & ${ }_{\text {II }}^{\text {Diluter }}$ & $\begin{array}{c}\text { Sperm } \\
\text { susp. }\end{array}$ \\
\hline$I$ & 1 & & & & 4 & 1 & ] \\
\hline II & 1 & & 1 & & 1 & 2 & 1 \\
\hline III & 1 & 1 & 1 & & & 3 & 1 \\
\hline IV & 1 & 1 & & I & & 3 & $\hat{1}$ \\
\hline
\end{tabular}

B. Order of adding reagents, and AAI:s found.

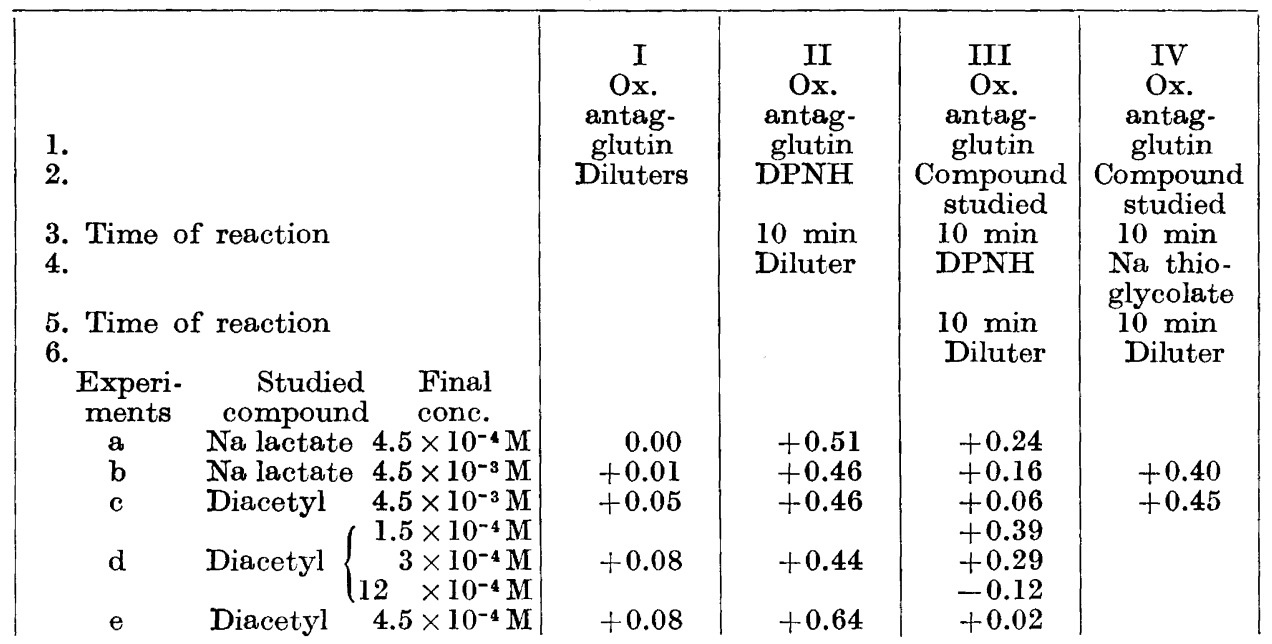

How the ability of inhibiting the reaction between DPNH and oxidized sperm antagglutin is connected with the structure of the compounds studied is so far poorly understood.

\section{DISCUSSION}

The easiness with which the sperm antagglutins are oxidized into a biological inactive compound, and are reactivated by reducing agents is notable. The inhibition of the reduction of oxidized antagglutins by sodium bisulphite points to a carbonyl or possibly a quinone-like structure in the oxidized antagglutin. It is thus probable that at least one hydroxyle in the reduced form is oxidized into a carbonyl, when the antagglutins are reversibly inactivated at oxidation. Depending on stereochemical configurations quinones may react with sodium bisulphite either irreversibly producing hydroquinone sulphonic acids or reversibly leading to $\alpha$-hydroxysulphonic acids like those of aliphatic carbonyl compounds. A quinone should have a specific absorption 
in the ultra-violet part of the spectrum. The oxidized male sperm antagglutin, however, has the same absorption curve as the reduced antagglutin ${ }^{3}$. This speaks against a quinone-like structure in the oxidized male sperm antagglutin.

On previous occasions a compound has sometimes been extracted in this laboratory with ethyl ether from male sperm antagglutin, and spectrophotometrically compared with tocopherols ${ }^{5}$. This aromatic compound seems to be of diphenolic character as it gives after oxidation a substance with a quinonelike spectrum in ultra-violet light. It appears most probable that this aromatic compound is an artefact, originating from an aliphatic precursor bound in the antagglutin molecule. When male sperm antagglutin is heated in molten potassium bisulphate, a product is formed which has some properties in common with corresponding products obtained in the same way from $\alpha$ - and $\delta$-tocopherols, and also with $p$-benzoquinone disulphonic acid ${ }^{12}$.

It is a notable fact that the reduction of oxidized antagglutins with DPNH is a non-enzymatic reaction. Carbonyl compounds are inert to DPNH, whereas a compound as $p$-benzoquinone is reduced by DPNH ${ }^{13}$. From this it is obvious that the carbonyl group of the oxidized antagglutin is more reactive than those, e.g., in sugars, having other neighbouring groups. In this connection it must, however, be stressed that we have not been able to detect ascorbic acid as a constituent of the sperm antagglutin.

Acknowledgements. This study was aided by grants from the Population Council, New York, the Swedish Natural Science Research Council, and the Swedish Medical Research Council. We are very much indebted to Drs. B. Ström and T. Svensson for semen material. We thank Mr. O. Heidenberger for valuable technical assistance.

\section{REFERENCES}

1. Lindahl, P. E. and Kihlström, J. E. Proc. II Intern. Congr. Animal Repr., Copenhagen 1952 , p. 70 .

2. Lindahl, P. E. Proc. III Intern. Congr. Animal Repr., Cambridge 1956.

3. Lindahl, P. E. and Kihlström, J. E. Fertility and Sterility 5 (1954) 241.

4. Kihlström, J. E. Arkiv Kemi 7 (1954) 399.

5. Lindahl, P. E., Kihlström, J. E. and Ross, S. Acta Chem. Scand. 10 (1956) 1597.

6. Lindahl, P. E. and Kihlström, J. E. Nature 174 (1954) 600.

7. Lindahl, P. E., Kihlström, J. E. and Ross, S. Acta Chem. Scand. 11 (1957) 1.

8. Lindahl, P. E. and Nilsson, A. Biochim. et Biophys. Acta 25 (1957) 22.

9. Lindahl, P. E. J. Repr. and Fertility 1 (1960). In press.

10. Phillips, P. H. and Spitzer, R. R. J. Dairy Sci. 29 (1946) 407.

11. Burton, R. M. and Kaplan, N. O. J. Biol. Chem. 206 (1954) 283.

12. Ross, S. Acta Chem. Scand. 13 (1959) 409.

13. Wosilait, W. D. and Nason, A. J. J. Biol. Chem. 206 (1954) 255.

Received June 4, 1959. 